\title{
The Issues of Residential House Systems and How to Make It More Sustainable Systems
}

\author{
Ahmad Riyadh Ahmad \\ College of Environmental Science and Technologies, University of Mosul, Iraq
}

\begin{abstract}
This paper highlighted a set of issues facing the residential house system and makes it unsustainable systems including: high energy consumption, high water demand, waste generation, and carbon dioxide emissions. The boundaries, inputs and outputs of residential house systems are displayed in detail and illustrated by modeling these systems for the purpose of understanding the relationships and interactions between these inputs and outputs and components of these systems. Thus, presenting a range of strategies that can be implemented to make residential house systems more sustainable and reduce the negative impacts of these systems on the environment and other sources such as water, energy and non-renewable resources to a minimum level.
\end{abstract}

Keywords: Residential house, unsustainable systems, modelling, interactions, inputs, outputs, negative impacts.

\section{Introduction}

The remarkable changes that have occurred in recent decades represented by the increased growth in the population, economic inflation, the evolution of technology, and environmental degradation have led to increase the demand for the use of sustainable systems in all aspects of life. Because the sustainable systems will contribute to minimizing the negative impacts on the humans, economics and environmental. The system concept is usually used to refer to a group of elements or components associated and interacting with each other, and each of these components possesses certain properties which collectively form the general properties of the system $(1,2)$.

The residential house system is one of the important systems that requires to take sustainability concept into consideration due to its strong association with human life, resources consumption and the environment. Here, the sustainable house can be defined as, the house with less or minimum negative effect on environment and other sources such as water, energy, and non-renewable materials (3). In order to understand the residential house system integrally, it must initially determine the system boundaries, the whole system inputs and the outputs of the system. Then, employ these inputs and outputs to draw up a model of the system.

Hence, this paper will identify the boundaries of residential house system and displays the different types of system inputs and outputs which will be used in the drawing the model of the whole system. Finally, the paper will describe a set of important issues that facing most of the residential houses, which include: high energy consumption, high water demand, waste generation, and $\mathrm{CO}_{2}$ gas emissions. With explain of some strategies that can be implemented to reduce the effect of these issues and consequently make the house more sustainable.

\section{The boundary of the residential house system} In general, any system usually has a number of boundaries, can includes physical, economical, logical, social, political and environmental boundaries. In the case of residential house system, the physical boundary 
refers to the geographical components of the house system such as, the house's buildings, gardens, garages and courtyards. The environmental boundary include, neighbor's houses and gardens, public parks, amusement park and stadiums, recreation places, market, workplaces to house residents (office, university, school, nursery school), and waste disposal places. While the economical boundary represent all resources that are owned by the house, which include for example, cars, motorcycle, bikes, tanks, swimming pools, swing, tools and equipment used in the irrigation and cleaning of the house garden and garage. Whereas the logical boundaries can be defined as all the activities that are controlled by the house and contributes to the house outcomes, such as the work of house occupants in their office or other daily jobs and the transport from and to the house. Social boundary involves the house occupants and visitors, friends, parties and barbecue that is held in house, social clubs, cleaners and maintenance workers, are considered another important types of boundary of residential house system. Political boundary of the house can comprises, heritage and culture of the residents, planning regulation and government and local authority legislation and Acts.

\section{The residential house system inputs and outputs}

In general, the residential house system contains a set of different inputs which include, energy, money, water, food, paper, bags and packages, equipment and appliances, and maintenance. These inputs in turn interact with components of the system and produce various types of outputs comprising cost, wages and bills, $\mathrm{CO}_{2}$, smog, hot air, waste water and detergents, damaged equipment and materials, waste food, paper, packages, plastic, glass, cartons and mineral containers. This section will display these inputs and outputs and shows the model of the whole house system as the following: a. Energy: Energy in its various forms (e.g. electricity, fuel, gas, coal) is considered one of the key inputs in the house system, which is characterized by a broad interference with the system components. The use of energy for different house demands causes in produce a variety types of outputs including bills, $\mathrm{CO}_{2}$, hot air, and $\operatorname{smog}(4,5,6)$.

b. Money: The operation of the entire house system mainly depends on the flow of money into the system. This input controls the supply of energy, water, food, appliances, equipment and various tools used to the house (7). The interaction of money with all the requirements of the house can consequently lead to the production of a wide range of outputs such as waste in all forms (water, energy, material, food, paper, etc.), wages, and bills.

c. Water: This input is comprised of water that is used for drinking, cooking, washing, cleaning, bathing, and irrigation (8). The main outputs that result from this input are the waste water, detergents, and bills. The amount of this outputs are usually controlled by the demands and behaviors of house occupants and also the numbers of those occupants (9).

d. Food: The consumption of various foods such as vegetables, fruits and grains in addition to readymade foods are a major source of many outputs involving leftover food, waste water, pots, and disposable plastic, mineral, and carton food containers (10). For example during the cooking process, the washing of raw food materials produce a lot of waste water and then the cooking of these raw materials by oven or cookers causes in consumption of energy and emission of $\mathrm{CO}_{2}(11)$.

e. Paper, bags and packages: Paper and bags from the inputs that must be taken into account with respect to the house system because of their use in abundance by the occupants of the house. Where the 
paper is used in a large quantity in most cases for the purposes of study and work. This consumption of paper will lead to output of a lot of waste paper (12).

As for the input of bags and packages, it can be argued that this type of input is strongly linked to the shopping rate, which ends up in the garbage.

f. Equipment \& appliances: The equipment and appliances of house system such as the TV, internet devices, computer, Vacuum cleaner, and other devices play a significant role in house system (13). Where the work of all of these devices depends mainly on the availability of electricity, therefore they will contribute to the energy consumption and bills.

g. Maintenance process: The house system needs continuously to maintenance operations for the purpose of repairing damages. During maintenance operations a variety of types of devices and equipment may be used, which in turn may need energy and water to run. Consequently, all these processes will eventually lead to the production of wages, waste water, waste material, plastic, glass and carton (13).

h. Inhabitants behavior: Inhabitants behavior and demands one of the house's inputs and simultaneously play a significant role in controlling of the rest inputs and outputs of the house system (13). Where the consumption rate of energy, water, food, paper and the resulting of different waste and $\mathrm{CO}_{2}$ depends to a large extent on the occupants number and behavior. Also inhabitant's behaviors and demands have an intrinsic role in driving maintenance process and household income and related bills, taxes and wages (13).

\section{Residential house model}

The following figure (1) has drawn to represent the model of the whole house system and shows how the inputs interact with the system components, the factors that affect this interaction and the type of outputs that results from this interaction. The increasing demand for energy and water sources from one hand and increase waste/rubbish productions and the exacerbation of climate change problem caused by $\mathrm{CO}_{2}$ emissions on the other hand. It has become necessary to consider these problems/challenges and the performance of residential house systems and try to make vital adjustments and design houses in efficient ways that assist to make them sustainable systems with less impact on the environment. Hence, the following part of this research will describe in more detail these challenges and some

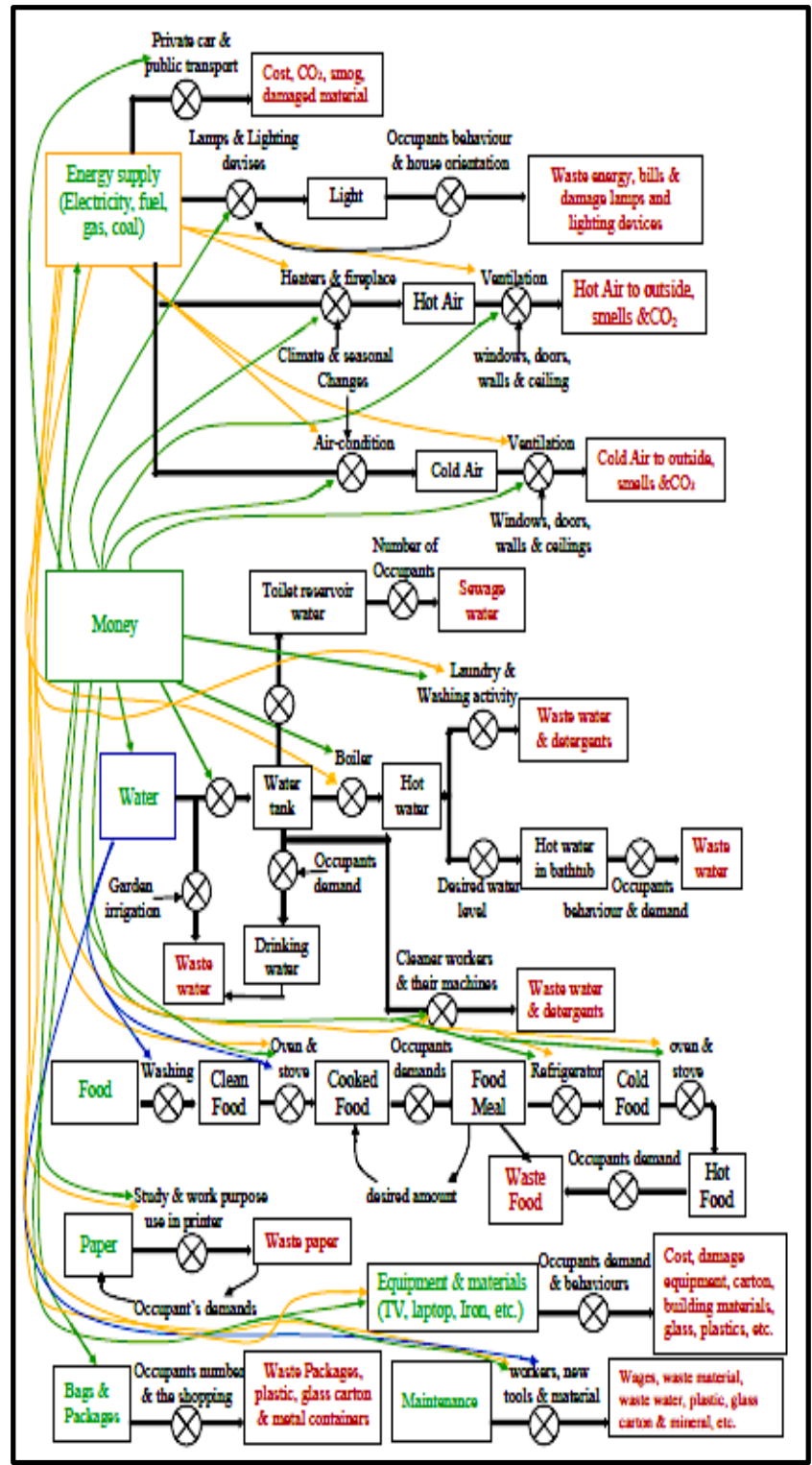

strategies that can be implemented to fix or reduce it. 
Figure 1: The residential house Model.

\section{High energy consumption}

In residential house system, high consumption of energy is one of the main issues that requires to solve in order to make the system sustainable. In the UK about $47 \%$ of national energy are spent by the residential houses sector (14). Most of the energy (electricity, gas, fuel, and coal) processed for house, reach about $60 \%$ of total supplied energy is often disbursed for the purposes of heating, cooling, ventilation, lighting, and water heating. While the remaining part of energy is consumed for other aspect such as refrigerating, cooking, various home appliances operation, maintenance process and transportation (15).

\subsection{House heating \& cooling system}

The use of poorly designed heating and cooling systems and traditional equipment such as kerosene stoves, gas heaters and old air-conditioners often cause an increase in electricity and fossil fuel consumption (5). Hence, it is crucial to adopt some modifications and alternative ways that ultimately lead to the achievement of the required heating and cooling in a sustainable manner and with less energy used.

One of these adjustments is supplying a thermostat sensor for the heating and cooling systems which will assist to control the turn on and off of these systems in accordance with the room temperature (16). Another very useful way to reduce energy consumption is to rely on a passive house design which is defined by Passive House Institute as a building that can provide a desired temperature without relying on heating and cooling systems, where it has claimed that about $75-90 \%$ of energy consumed for heating and cooling can be saved by using this type of house. There are various elements of the passive house including the use of sun to heat the house in winter and utilization of shading strategy in summer to cool the house by establishing of green walls (trees) around the house. Another passive house element is the use of windows and building materials and covering of walls, roofs and floor slab which are characterized by high isolation capacity in order to keep the heat and cold within the house (13).

In general, the utilizing of passive heating and cooling system not only decreases the energy consumption but it contributes also in reducing the annual cost for heating and cooling by more than $40 \%$ (17). Heat recovery ventilation and hot water recovery techniques are also among other methods that can used in heating the house, which in turn will decrease the requirement of energy (13). The change in inhabitant's behaviors can also reduce energy demands for heating and cooling.

\subsection{Ventilation system}

The continuous ventilation of the house by using fans and ventilation system in order to get rid of moisture, undesired odors and gases and obtain healthy and comfortable air quality is one of aspect that causes in high energy exhaustion. However this consumption can be diminished through providing residential integrated ventilation controller system (RIVC) to the conventional ventilation systems (18). This system controls and coordinates the operation and turn off ventilation systems automatically in response to air quality inside the house, such as increasing the percentage of moisture of the air, it also limits the operation of ventilation fans when the air outside the house contaminated and nonpure (19).

Another strategy is the use of passive and hybrid ventilation which depends on the utilization of natural wind and stack effect (Fig 2) to provide ventilation to the house with the use of mechanical control to arrange airflow to the house and keep it within the required level (18). In addition, the resident's behavior through the opening of windows and doors several times during the day usually have a positive effect on the ventilation 
process.

However, the use of passive ventilation may not be feasible in regions where the air is most frequently polluted with dust, smoke and the rest of the air pollutants from surrounding industries, roads, open and bare land. For example, In most of Iraq's provinces there

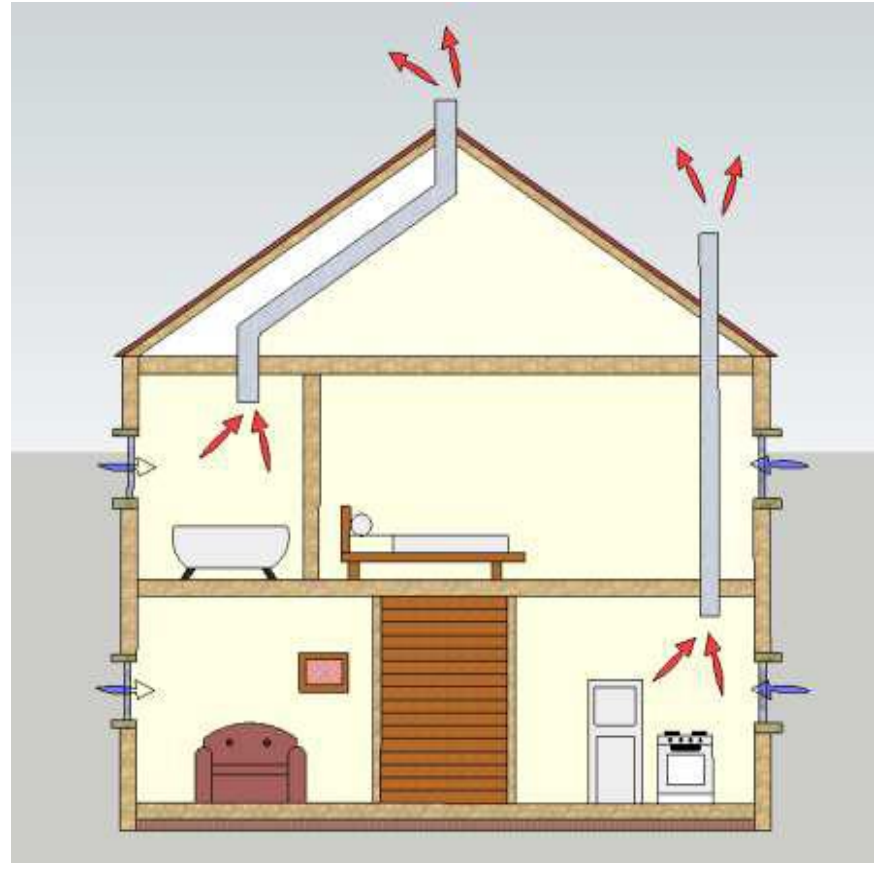

are in every region of the province approximately four to five of huge civil generators to feed the electricity for the region, these generators uses of diesel fuel, causing in emission of massive amounts of smoke covers the entire region making passive ventilation technique is very limited to use by the houses in this region.

Figure 2: Passive stack ventilation (18).

\subsection{Lighting System}

Lighting is from the house components that is responsible for relatively high levels of consumption of incoming electricity to the house. For example, the rate of electricity disbursed on house lighting in the USA representing $10 \%$ of the total electricity contained to the house (15). However, according to the IPCC 2007(11) there are a set of options which can be implemented in order to avoid high energy consumption for lighting including:

a. the use of compact fluorescent (CFLs), halogen and
LEDs lamps, that are characterized by low energy required to run and contribute in saving money. Where the use of CFLs lamps instead of incandescent light bulbs can reduce over $10-20 \%$ of lighting bill (20);

b. Add of motion and daylight sensors to the lamps, which will assist to turn off the lights automatically during the daylight and in the vacant places within the house;

c. Utilization of daylight through designing the house in way that allows to provide the maximum amount of light to the house, for example make the windows large in size and distributed enough around the house. Also the using of daylight can help in saving about $20 \%$ of lighting cost (20). However, the cloudy weather on

d. most days of the year and the physical boundary of the house such as neighbor buildings and trees can decrease and obscured light from reaching home, thus reducing the efficient use of daylight;

e. Paint the house with light colors and avoid the use of dark colors that absorb light;

f. inhabitants behavior such as use the minimum number of lights and turn off the lights when leaving the room also has a significant role in reducing energy consumption and related bills/costs and increasing the lamps lifetime and reduce damaged lamps.

\subsection{Refrigerators}

In general the average amount of electricity consumed in residential house by refrigerators in developed countries is estimated at about $12 \%$ of the total electricity of the house (13). Where in the EU the ratio reached to $15 \%$ in 2004 (21) while in the USA it was 8\% in 2005 (22). Therefore it is necessary to implementation some strategies and adjustments in order to gain lower energy consumption for refrigeration. From these strategies is 
optimize insulation performance and seals door, increase the efficiency of compressor. These options are implemented virtually in 'Arçelik refrigerator' which manufactured in turkey and resulted in a marked decrease in electricity consumption (13). Where the use of a multi-speed compressor has assisted in running compressor at low levels without the need to stop completely during the arrival of the temperature inside the refrigerator to the required degree, consequently it assisted in conservation of high-energy that was consumed during re-operation of the compressor after a stopover (13).

In addition, the use of (1) a top-mounted cooling system that allows the heat generated by compressor and condenser to escape away from the unit; (2) high insulation material within the walls such as, polyurethane foam; (3) separated air flow strategy to separate refrigerator section from freezer section, thus no air loss from one of these sections during the open the door of the other section, can lead to the low electricity consumption. This is evidenced by the Sun Frost refrigerator that made in the US which has employed these strategies in its design. Where the consumption of energy reduced by up to $80 \%$, consequently the relevant electricity bills decreased also (13).

\subsection{Heating water}

The domestic demand for hot water is also another aspect that causes high energy consumption within the house system. For example in china, the EU, and the US, the energy that spent for heating water in residential house reached about 27\% in 2000 (23), 9\% in 2004 (24), $11 \%$ \& $13 \%$ in 2005 \& 2012 respectively $(15,22)$ of total house energy for each country respectively. Hence it is

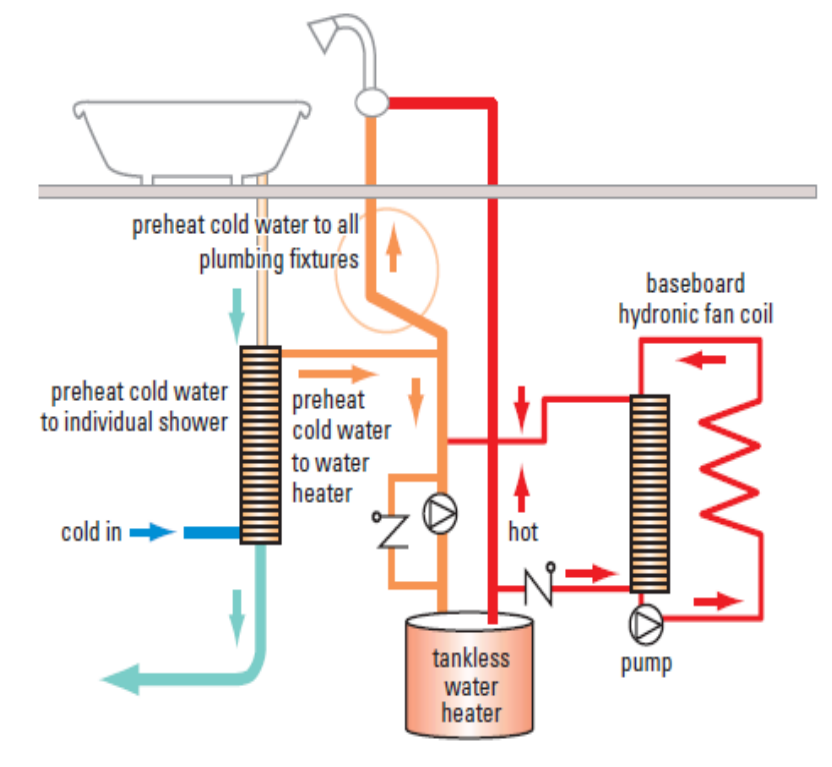

important to conduct some steps for reducing energy consumption in this aspect. Such as replace the electrical storage systems with gas storage systems which have smaller storage units that enhance heating and recovery water heat in short time (13). Therefore it is considered more efficient than electric storage systems and lead to saving energy reaching $30 \%$, thus reducing the money required for bills/taxes (25). However, the combination of a solar thermal system or a heat pump with the electric storage system can contribute to making this system more efficient with regards to reducing energy requirement (13) and also help in saving approximately $325 \$$ per year (26).

The action of insulation tanks and hot water pipes via covering them by for example 'split foam rubber', also will lead to preventing the loss of heat by $20-45 \%$ consequently reducing the energy demand for reheating of water (27). Other strategies that play a role in reducing energy consumption by $12-15 \%$, is the organize 
running water heating system and provide a timer to it and ensure of switching off during the day periods when the need for hot water is low, such as when the occupants are at work or on vacation (27). Drain-water heat recovery by using of a gravity film exchange drainwater heat recovery system (Fig 3) is also a very useful strategy which can save about 20-30 \% of energy consumption and simultaneously saving money and reduce waste heat (26).

The behavior of the occupants also can play a positive role in this aspect via, for example, reduce the number of times of shower during the day or week, aggregation of unclean eating utensils or clothes and washed at one time instead of washing it individually, monitor the children behavior's and prevent them from tampering and leave the hot water tap open. This measures, will assist also in decreasing the demand for water, minimising water/energy bills and produce of waste water.

Figure 3: Drain-water heat system (26).

\subsection{Appliances}

The various appliances, such as Ovens, TVs, computers, clothes washer, DVD players, gaming consoles, mobile phone chargers and others, are considered among the most important house components responsible for high energy consumption. Where they contributed in consumption of about $25 \%$ and $27 \%$ of house energy in EU-15 (21) in 2004 and US in 2005 (EIA, 2006) respectively.

The energy consumption by house appliances can be reduced through the adoption of some strategies such as, use of Liquid crystal display (LCD) TVs and Light emitting diode (LED) TVs instead of Plasma TVs (28). Although the prices of LCD TVs and computer monitor is relatively expensive but at the same time it considered a low cost compared to the excess electricity bills produced in the case of the use of traditional TV and computer monitor. The use of LCD TVs usually lead to decreasing the energy used by $80 \%$ (28). Also the use of LCD monitor of computer can result in a decrease in used energy by 30-45\% lower than energy used in traditional computer monitor (28), thus reducing of extra energy bills.

As for the oven appliance, it preferred to use of oven just in case of preparing large meals, whereas it is better to rely on microwave and solar cooker in preparation of the small meals, which will reduce energy consumption by approximately two-thirds less than conventional ovens (26). However, there are some evidence and studies have indicated that the use of microwaves can cause a change in the composition of the food components may reduce or lose their nutritional value and may also cause the formation of harmful compounds to human health. Therefore, these studies recommended to avoid or minimise the use of microwave to a less extent possible. As for the clothes washer, $50-70 \%$ of energy can be saved by using of horizontal-axis (H-axis) loading washers instead of vertical axis washer (29).

It should be noted that the increasing public education and awareness through education programs carried out by local authorities and educational establishments such as advertising, television programs, guiding posters and workshops, can effectively contribute to reducing energy consumption, decreasing bills/taxes, and minimising production of different wastes in all the above aspects (heating \& cooling, Ventilation, lighting, Refrigerators, Heating water, Appliances) (30).

\section{High water demand}

The residential housing sector is considered among the highest sectors of water consumption. Where the use of water in this sector has been calculated at about $8 \%$ of global water extraction and this ratio reached $13 \%$ in some places, such as Europe (13). It is noted that the 
domestic water demand in developed countries is usually higher than that for developing countries, where the quantity used by each person in the developed countries has been estimated at 500-800 liters per day compared with only 60-150 liters per day per capita in developing countries (31). This high consumption usually comes from unsustainable and misuse of water in the showers, toilets, laundry, washing, kitchen and gardens (31). Therefore, it is crucial to implementation some of the measures that can assist in reducing the excessive consumption of water in the residential house. Water efficiency measures is considered one of the very successful strategies that can save over 60 percent of water demand. These measures include use of low-flow aerators for taps, dual-flush toilets, efficient shower heads and water-efficient appliances such as new efficient front-loading model which can conserve about 10,000 liters of water per year comparing to the old washer model (32). Another useful strategy is the use of rainwater tanks and greywater recycling systems to meet the house demands for water. Water captured by rainwater tanks and water from recycling of greywater (water that result from showers, basins, taps and nontoilet water) can be utilized effectively after conduct a suitable treatment on it in laundry, shower, toilet flushing, and irrigate of garden. Consequently the demand for water will diminish dramatically (33). This method has been successfully implemented in the re-use about $80 \%$ of gray water for irrigation of gardens and toilet flushing in 3500 residential house in Mawson Lakes in South Australia (34).

Using dual reticulation is also from measures that can decrease the consumption of domestic water. Where this network enable from use recycled water and drinking water, together to supply the house by the required amount of water, therefore it can assist in reduction about $80 \%$ of water consumption (35). Moreover, 'water-sensitive garden design' is also an important measure that must be emphasized on it during the formation of the house garden. Because about $60 \%$ of house water usually spent on watering the garden (33). In order to reduce this percentage, it prefers to plant drought-resistant plants that consume small amounts of water, set up a drip irrigation system, and planting trees that characterized by few water consumption around the garden, which in turn will provide the proper shading and reduce the evaporation of water from the garden.

All previous mentioned strategies contribute effectively in reducing water demand, saving a large amounts of money which were paid for bills and taxes and also decrease the produce of waste water. However, the inhabitants behavior in dealing with water is consider one of aspects that can also play a significant role in decreasing the demand for water and related bills and waste water production. For example, repairing of water taps that can not be closed tightly, not leaving the water tap open while cleaning the car, minimising the number of times and period of washing cars, laundry, and shower, and reducing parties and gatherings with friends held in the house and replaced it by meeting in social clubs, bars and parks. In addition, teaching children in schools, putting posters in public places, and organize awareness campaigns on the importance of water conservation and reducing consumption, as well as increase the taxes, and issuing legislation by the competent authorities are also very important in this area.

\section{Waste generation}

The recent years have seen a marked increase in the rate of household waste production globally. Where during the daily lives of the occupants of the house, they produce high amounts of waste that cause negative returns on household income and the environment. According to the DEFRA (2004) about 9\% of total UK 
wastes usually come from the residential house sector. The main component of the household waste is often the paper, food, bags and packages (e.g. plastic, glass, and metal containers). For example, in Australia the food waste comprise $40.2 \%$ of total house waste while paper, plastic, and class compose $19.7 \%, 10 \%, 4.1 \%$ respectively (12).

Hence, the overcome of high household waste production requires the application of a set of strategies that can through it achieve effective management of the house waste. One of the most important among these strategies is prevent the production of waste through for example, (1) buy (or cooking) food or use of materials as needed and avoid unnecessary consumption; (2) use of foods and products with a long-term expire date and do not cause producing of large amount of waste when it is used; (3) utilize of leftovers in fertilizing the garden or feeding of animals that are bred at house; (4) use of material that can be used for several times such as using canvas or leather bags instead of the use of plastic and paper bags and also use of cloth napkins instead of paper plates or paper towels; (5) repair and maintenance of tools and equipment or return it to the company produced and replaced with new ones versus payment of a simple financial differentiation $(36,37)$.

Another effective measures is re-use and recycling of the components and material that will be disposed as waste (38). Such as, (a) recycling cans, glass bottles and containers, plastic and paperboard package; (b) reuse of paper, paperboard, cartons, and Newspaper by inhabitants as drafts to write notes during study, packing and covering materials, or formation of art and three-dimensional shapes in nurseries and school; (c) reuse of plastic and glass containers to storage of food and other materials or in case of water containers, It can be refilled and reuse again (39). In general, all the occupants behavior and the measures of reduction, recycle and re-use of solid waste and garbage, that mentioned above, usually assists in decreasing the waste collection bill to a very low level and saving money that required to buy new stuff, equipment and material.

\section{8. $\mathrm{CO}_{2}$ gas emissions}

The issue of $\mathrm{CO}_{2}$ emission is one of the major issues facing the residential house system and causes significant negative impact on the environment. Where the residential houses sector contributes in the emission of large amounts of $\mathrm{CO}_{2}$ gas into the air annually, which in turn increases the problem of climate change. For example, in the UK the rate of $\mathrm{CO}_{2}$ emitted from houses for the period between 1990 and 2006 reached about 40\% of the total $\mathrm{CO}_{2}$ emissions $(40,41)$. Most of house $\mathrm{CO} 2$ emission come from the use of energy (electric, fuel, gas, and coal) for heating, cooling, water heating, cooking and operation appliances $(11,13)$.

However, the $\mathrm{CO}_{2}$ emissions can be diminished through adopting some actions such as: (1) reduce the consumption of energy and use of renewable energy (solar energy, wind power, geothermal, biomass) as an alternative of fossil fuel; (2) use of efficient and advanced technologies and appliances that need small amount of energy such as LED TVs, LCD computer monitor, $\mathrm{H}$-axis loading washers, microwave, etc.; (3) maintain and repair devices that causes high $\mathrm{CO}_{2}$ emission such as household electricity generators; (4) adopt a passive house style in house design, which is characterized by using of super insulation materials within his structure in addition to the use of very low amounts of energy for heating, cooling and ventilation the house because it relies on passive heating, cooling, and ventilation system as it mentioned earlier; (5) enhance the occupants to use public transport instead of private cars and avoid unnecessary use for cars; (6) also the inhabitants behavior is very important such as, avoid leaving fireplace and kerosene heaters operated In times of the 
day where the need for heating is low, during work periods or in unoccupied rooms and prevent the burning of waste and rubbish; (7) Enact and issuing legislation obligate homeowners to reduce carbon emissions and put extra fines and taxes on homes that release carbon at high levels $(11,40)$.

In general, the reduction and elimination of emission of $\mathrm{CO}_{2}$ from house by applying aforementioned solutions has great benefits includes: (a) the improvement of air quality inside and outside the house; (b) reduce the problem of climate change; (c) avoid the problem of fuel poverty; (d) increase households income, employment opportunities, and national energy security; (e) the use of public transport and implementation of works, businesses and shopping through using the internet can contribute effectively in reduction of transport wages and fuel cost (40).

\section{Conclusion}

Residential house system is considered one of the important systems that associate strongly with people daily life. This system consists of a number of elements which make up the entire system. House system usually has a set of inputs that interact directly with components of the system and lead to the production of a set of outputs. The type of these outputs depends mainly on the nature of the interaction of the system components with the inputs, the occupant's behavior, the economic factors and the effect of environmental aspects on the system. Therefore, it is necessary to focus on these interactions and the outputs and try to model it, in order to make the system more clear and easy to understand and also to identify aspects and issues that negatively affect the system and then develop appropriate solutions, with consideration for the economic and environmental aspects during the selection of these solutions.

In residential house there are four main problems encompass high energy consumption (heating \& cooling, ventilation, refrigerators, heating water, and appliances), high water demand, waste generation, and $\mathrm{CO}_{2}$ gas emissions. These problems can be treated by implemented some technical modification and measures such as: use of passive heating, cooling and heating water system, passive and hybrid ventilation, CFLs bulbs, solar photovoltaics, geothermal pump, waterefficient appliances, rainwater collection system, and reuse of graywater, reduction, recycle and reuse of waste, use of renewable energy instead of fossil fuel to reduce $\mathrm{CO}_{2}$ emission.

Change in inhabitants behaviour is another technique can decrease the volume of these issues effectively such as turn off the heating and cooling, lights and other devices when leaving the room or the house, aggregation of unclean eating utensils or clothes and washed at one time instead of washing it individually, not leaving the water tap open while cleaning the car, meeting friend at social club and parks instead of home, and use of public transport as alternative of private cars. Issuing legislation and Acts, increase taxes, increase public awareness by putting posters in public places, and organize awareness campaigns by the competent authorities, are also considered very successful ways that can use to reduce the problems that facing the house system. Consequently all these actions (technical measures, change in inhabitants behaviour and Issuing legislation and Acts), will also lead to decrease required bills, wages and taxes and increase conservation of environment.

It should be noted that the role of all the strategies and measures mentioned above are not confined only to solve the problem with a particular input or output in the system, but it may directly affect the rest of the system inputs and outputs. for example, the using of Drain-water heat recovery or change the inhabitants 
behavior through avoid leaving the hot water tap open for a long time during the washing, will not only reduce hot water consumption, but also will lead to reduced demand for water, energy consumed for heating water, $\mathrm{CO} 2$ emissions from burning fuel for heating water, saving energy/water bills. Therefore, when selecting solutions that will be implemented, it must consider in their compatibility with the rest of the system inputs/outputs. i.e., it should avoid solutions that may lead to the formation of larger and more complex problems for the other inputs or outputs.

\section{References}

1. Skyttner, L. (2006). General Systems Theory: Problems, Perspective, Practice. $2^{\text {nd }}$ edn., World Scientific Publishing Company: $521 \mathrm{pp}$.

2. Amagoh, F. (2008). Perspectives on organizational change: systems and complexity theories. The Innovation Journal: The public sector innovation journal, 13(3), article 3:1-14.

3. Priemus, H. (2005). How to make housing sustainable? The Dutch experience. Environment and Planning B: Planning and Design, 32(1):5-19.

4. Newman, P and Kenworthy, J. (1999). Sustainability and cities: overcoming automobile dependence. Washington, DC: Island Press: 442 pp.

5. Nidumolu, R.; Prahalad C.k. and Rangaswami M.r. (2009). Why sustainability is now the key driver of innovation. Harvard business review, 87(9): 56-64.

6. Praznik, M. Butala, V. and Zbašnik-Senegačnik, M. (2014). A simple method for evaluating the sustainable design of energy efficient family houses. Strojniški vestnik-Journal of Mechanical Engineering, 60(6): 425-436.

7. Wilson, A.; Thorne, J. and Morrill, J. (2003). Consumer Guide to Home Energy Savings. 8thedn., Washington, DC: ACEEE: $256 \mathrm{pp}$.

8. Kruger, P. (2006). Alternative energy resources: the quest for sustainable energy. Chichester: John Wiley: $272 \mathrm{pp}$.

9. Gleick, P.H. (2014). The World's Water Volume 8: Island Press: 496 pp.

10. Department for Environment, Food \& Rural Affairs (DEFRA). (2004). [Online], Available at: http://www.defra.gov.uk/environment/statistics/wast e/alldefs.htm.

11. IPCC. (2007). Climate Change 2007: Mitigation of Climate Change, Contribution of Working Group III to the 4th Assessment Report of the Intergovernmental Panel on Climate Change. Cambridge University Press: Cambridge.

12. Department of Environment, Climate Change and Water (DECCW). (2011). Reducing Waste: Implementation Strategy 2011-2015. Department of Environment, Climate Change and Water NSW.

13. von Weizsä̈ker, E.; Hargroves, K.; Smith, M.H.; Desha, C.; and Stasinopoulos, P. (2009). Factor Five: Transforming the Global Economy Through 80\% Improvements in Resource Productivity. London: Earthscan/The Natural Edge Project: 448 pp.

14. Wang, L.; Gwilliam, J. and Jones, P. (2009). Case study of zero energy house design in UK. Energy and Buildings, 41(11): 1215-1222.

15. U.S. Department of Energy (DOE). (2014). Annual Energy Outlook 2014. Energy Information Administration (EIA).

16. Haines, R.W. and Hittle, D.C. (2006). Control Systems for Heating, Ventilating, and Air Conditioning. $6^{\text {th }}$ edn., Springer Science \& Business Media: New York: 375 pp.

17. Yardi, R.; Smith, A. and Wang, K. (2004b). \#3 SPACE COOLING. RMI Home Energy Briefs, Rocky Mountain Institute, Snowmass, CO.

18. Turner, W.J. and Walker, I.S. (2012). Advanced Controls and Sustainable Systems for Residential Ventilation. Ernest Orlando Lawrence Berkeley National Laboratory: $99 \mathrm{pp}$.

19. ARB (2005). Review of the Ambient Air Quality Standard for Ozone. Sacramento, CA: California Air Resources Board.

20. Goorskey, S. Smith, A. and Wang, K. (2004e). \#2 Lighting. RMI Home Energy Briefs, Rocky Mountain Institute, Snowmass, CO.

21. Bertoldi, P. and Atanasiu, B. (2007). Status Report 2006: Electricity Consumption and Efficiency Trends in the Enlarged European Union, Institute for Environment and Sustainability.

22. Energy Information Administration (EIA) (2006) Annual Energy Outlook, EIA, Washington, DC.

23. Zhou, N. et al. (2007). Energy Use in China: Sectoral Trends and Future Outlook. Ernest Orlando Lawrence Berkeley National Laboratory, LBNL-61904: United States.

24. Waide, P.; Lebot, B. and Harrington, P. (2004). The historic and potential impact of residential electrical equipment energy efficiency policies in the OECD. In proceedings of the EEDAL'03 conference, Softech, Turin, Italy, 1-3 October.

25. Chris, R. (2008). Technical Manual: Design for Lifestyle and the Future. $4^{\text {th }}$ edn., Canberra: Australian Greenhouse Office: $348 \mathrm{pp}$

26. Goorskey, S.; Smith, A. and Wang, K. (2004b) \#5 Water Heating. RMI Home Energy Briefs, Rocky Mountain Institute, Snowmass, CO.

27. Goorskey S, Smith A and Wang K. (2004a) \#8 kitchen appliances. RMI Home Energy Briefs, Rocky Mountain Institute, Snowmass, CO.

28. Pears, A. (2004). Greenhouse Challenge for Energy, Report to Victorian Department of Infrastructure and Department of Sustainability and Environment, The Allen Consulting Group. 
29. Goorskey S, Smith A and Wang K. (2004c) \#6 Cleaning Appliances. RMI Home Energy Briefs, Rocky Mountain Institute, Snowmass, $\mathrm{CO}$.

30. Edwards, B. and Turrent, D. (2000). Sustainable Housing Principles \& Practice. London: E \& FN Spon: 182 pp.

31. UNESCO. (2000). Water Use in the World: Present Situation/Future Needs, United Nations Educational, Scientific and Cultural Organization.

32. Stasinopoulos, P.; Smith, M.; Hargroves, K. and Desha, C. (2008). Whole System Design: An Integrated Approach to Sustainable Engineering. Earthscan, London, and The Natural Edge Project, Australia: 208 pp

33. Department of Environment, Water, Heritage and the Arts (DEWHA) (2009), Annual report.

34. Hargroves, K. and Smith, M. (2005) The Natural Advantage of Nations: Business Opportunities, Innovation and Governance in the 21st Century. $5^{\text {th }}$ edn., Earthscan: London, The Natural Edge Project, Australia: 550 pp.

35. Bowmer, K.H. (2004). Water Innovation: A New Era for Australia. Lane Cove, NSW: CL Creations.

36. SEPA. (2007). Household Waste Prevention Action Plan (Scotland).

www.scotland.gov.uk/Resource/Doc/166848/0045564.p df.

37. EPA (2014) Reduce, Reuse, Recycle. [Online]. Available at: http://www2.epa.gov/recycle/reducing-and-reusingbasics.

38. Chartered institution of procurement and supply (CIPS). (2007). How to develop a waste management and disposal strategy.

39. Weinzierl, R.A. (1996). 57 Ways to Protect Your Home Environment (and Yourself): Cooperative Extension Service, University of Illinois at Urbana-Champaign: 310 pp.

40. Boardman, B. (2007). Home truths: A low-carbon strategy to reduce UK housing emission by $80 \%$ by 2050 . University of Oxford's Environmental Change Institute, A research report for The Co-operative Bank and Friends of the Earth.

41. DEFRA. (2007). UK Emissions of Greenhouse Gases, eDigest Statistics: Climate Change. [Online]. Available at: http://www.defra.gov.uk/environment/statistics/ globatmos/gagccukem.htm. 